\title{
Application of Molecular Imprinted Polymer Solid Phase Extraction (Mispe) in the Extraction of Caffeine From Coffee
}

\author{
Rozita Osman*, Norashikin Saim, Nurdiyana Mohd Anuar and Siti Norbayu Mohd Subari
}

Faculty of Applied Sciences, Universiti Teknologi MARA, 40450 Shah Alam, Malaysia

\begin{abstract}
Caffeine is naturally found in plant products such as coffee beans, cocoa beans and tea leaves. In this study, caffeine molecular imprinted polymer (MIP) was synthesized by dissolving 1 mmol caffeine and 4 mmol monomer, methacrylic acid (MAA) and 1mmol ethylene glycol dimethacrylate (EDMA) as the crosslinker and benzoyl peroxide (BOP) as the initiator. MIP exhibits significantly high affinity and selectivity for the target analytes used as the template than for similar molecules, including closely related isomers. The efficiency of extraction using caffeine MIP as sorbents in solid phase extraction (SPE) was evaluated. Good recovery $(91.6 \%)$ and low percent RSD (0.9 \%) was obtained using the spiked samples $(10 \mu \mathrm{g} / \mathrm{mL})$. The molecular imprinted polymer solid phase extraction (MISPE) technique was then applied in the extraction of caffeine from various coffee samples. Based on the excellent selectivity, MIP is a promising approach for the extraction of compounds from a complex matrix such as herbal extract.
\end{abstract}

Keywords: Molecular imprinted polymers, solid phase extraction, caffeine, coffee.

\section{INTRODUCTION}

Caffeine is a natural component of coffee, tea and cocoa, but may create health risks to specific group of consumer. Therefore the determination of caffeine in these plant products is important. Studies conducted on the effect of caffeine on our health revealed that there are differences between the effects of amounts of caffeine that are normally consumed and those observed when excessive amounts are ingested, or when very sensitive individuals are studied. Therefore, it is important to balance the benefits of caffeine and reduce or prevent adverse effects due to overconsumption or consumption at inappropriate times $[1,2]$

Molecular imprinted polymers (MIP) have been reported to exhibits significantly high affinity for the molecules used as the template than for similar molecules including closely related isomers. In recent years, MIPs have attracted much attention due to their outstanding advantages, such as predetermined recognition ability, stability, relative ease and low cost of preparation, and potential application to a wide range of target molecules [3, 4]. The main advantage that MIPs possess over conventional solid phase extraction packing materials is their specificity [5].

Caffeine MIP has been used as a sorbent in solid phase extraction of caffeine from green tea after four hours solvent extraction [6]. Conventional method in the determination of caffeine from a sample requires several steps, using a large amount of chlorinated solvent and time consuming [7]. Compared with traditional sorbents, MIPs can, not only concentrate but also selectively separate the target analytes from complex samples. Thus, the proposed technique (a

*Address correspondence to this author at the Faculty of Applied Sciences, Universiti Teknologi MARA, 40450 Shah Alam, Malaysia;

Tel: 03-55443861; E-mail: rozit471@salam.uitm.edu.my combination of MIP and SPE can specifically isolate and extract caffeine and thus provide a one step approach for an efficient and fast method in the determination of caffeine in samples such as coffee beans products. Previous work showed MIPs have been successfully applied to the pretreatment of analytes in foods, drugs, and biological and environmental samples in the past five years [8-11]. This work describes the preparation of molecularly imprinted polymer (MIP) and the application this polymer to solidphase extraction (MISPE) for the analysis of caffeine from coffee products.

\section{EXPERIMENTAL}

\subsection{Chemicals}

Caffeine standard was obtained from Sigma Aldrich (Seezle, Germany). Ethylene glycol dimethacrylate (EDMA), Benzoyl peroxide (BOP) and methacrylic acid (MAA) were purchased from Sigma-Aldrich (Seelze, Germany). All solvents used (dicloromethane, methanol, acetic acid) were of HPLC grade obtained from Merck (Darmstadt, Germany). SPE cartridges, packed with $500 \mathrm{mg}$ of $\mathrm{C}_{18}$ was purchased from Biotage (Europe).

\subsection{Molecular Imprinted Polymer Preparation}

An imprinting polymer was synthesized by dissolving 1 mmol caffeine and 4 mmol MAA in $50 \mathrm{~mL}$ dicholomethane in a two neck round bottom flask. The mixture was homogenized for $30 \mathrm{~min}$. Then, $20 \mathrm{mmol}$ EDMA and 1 mmol of initiator, BOP was added into the solution and the mixture were purged with a stream of nitrogen for $10 \mathrm{~min}$. Next the reaction flask were sealed and heated in a water bath at $60{ }^{\circ} \mathrm{C}$ for $24 \mathrm{~h}$. After the polymerization, the monolithic polymers obtained were ground in a laboratory mortar and pestle. In order to remove the remains of the monomers and the template, the polymer were extracted in a 


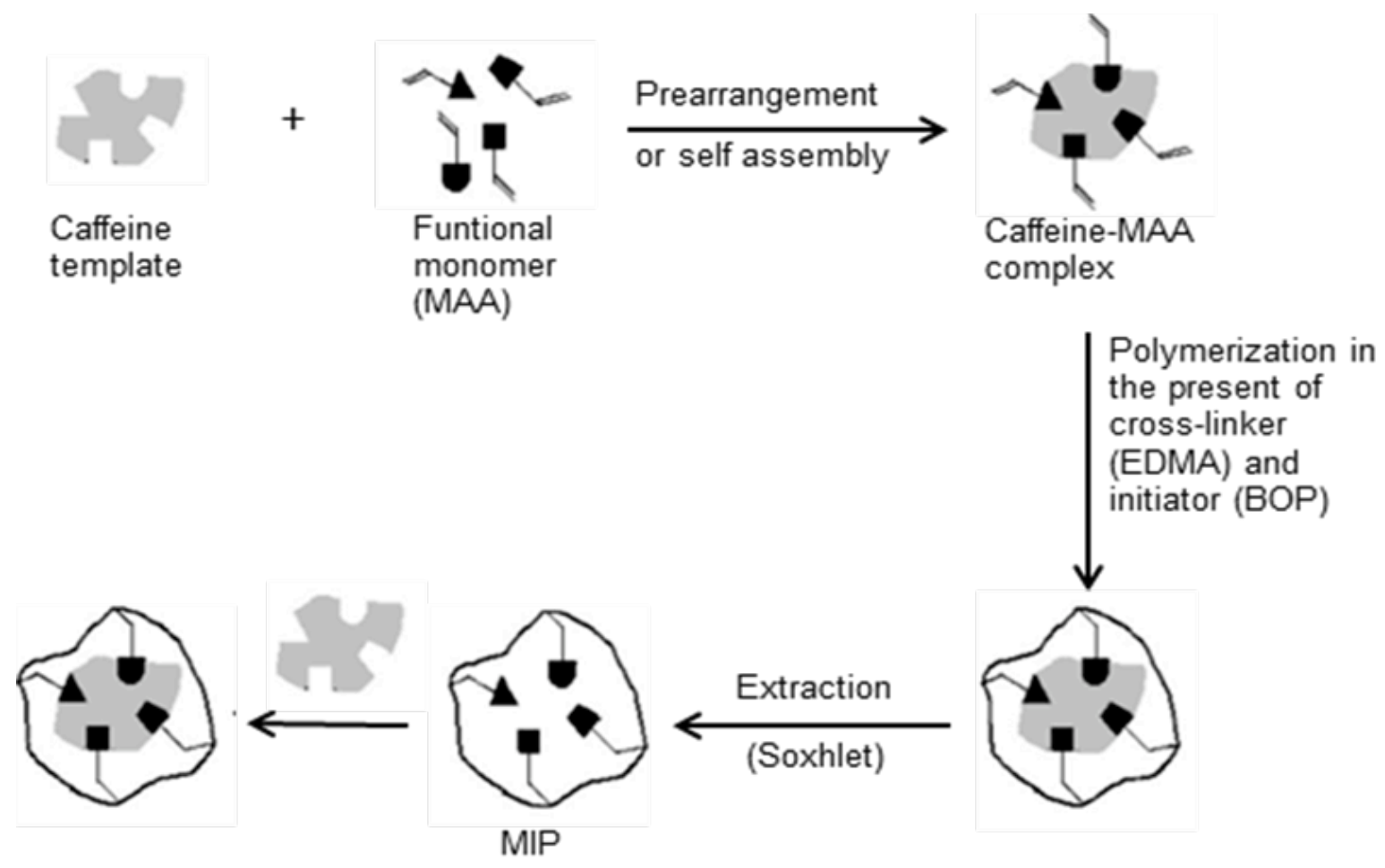

Fig. (1). Synthesis of molecularly imprinted polymers (MIPs) and its selective recognition to target molecule (caffeine).

Soxhlet apparatus using a mixture of methanol-acetic acid $(9: 1, \mathrm{v} / \mathrm{v})$ for $16 \mathrm{~h}$. To determine the effectiveness of the template removal, the concentration of caffeine in the extraction solvents was determined by high performance liquid chromatography (HPLC). The polymers were then dried and ground in a laboratory mortar and pestle to reduce the particle size and were dry sieved through $90 \mu \mathrm{m}$ sieves. Repeated grinding and sieving cycles were necessary to reduce the size of the particle. In order to verify that the retention of caffeine was due to molecular recognition and not due to non-specific binding, control non-imprinted polymers (NIPs) were prepared using the same procedure with the omission of the template.

\subsection{Solid Phase Extraction}

Commercial SPE cartridges were emptied from their packing materials. The cartridge tube and frits were then thoroughly cleaned and dried. About $200 \mathrm{mg}$ of the caffeine MIP polymers was packed dry in the cartridges and the upper first was placed on top. Before the extraction, the MIP cartridges were treated with methanol/acetic acid $(90 / 10$, vol. \%), 4 × $3 \mathrm{~mL}$, followed by methanol 4 × $3 \mathrm{~mL}$. C18 was treated only by methanol $4 \times 3 \mathrm{~mL}$. The extraction process involved loading the SPE cartridges with caffeine solution $(10 \mu \mathrm{g} / \mathrm{mL})$ or a sample of coffee solution, (the loading volumes were $1 \mathrm{~mL}$, respectively) washing with $1 \mathrm{~mL}$ methanol, and eluting. Eluting the caffeine from the MIP cartridge was done using $2 \mathrm{~mL}$ mixture of methanol:acetic acid $(90: 10, \mathrm{v} / \mathrm{v})$. All the applied fractions were collected and evaporated to dryness. The residues were reconstituted to solution with $100 \mathrm{~mL}$ methanol and analyzed using HPLC. The calibration curves were constructed to measure the amount of caffeine using standard solutions in the range of 0.25 to $50 \mu \mathrm{g} / \mathrm{mL}$.

\section{RESULTS AND DISCUSSION}

\section{Synthesis of Caffeine-MIP}

MIPs are synthetic polymers with highly specific recognition ability for target molecules. In the most common preparation process, monomers form a complex with a template through covalent or non-colvent interactions are then joined by using a cross linking agent [6]. In this study, caffeine MIP was synthesized by dissolving caffeine, monomer methacrylic acid (MAA), ethylene glycol dimethacrylate (EDMA) as the cross-linker and benzoyl peroxide (BOP) as the initiator. Fig. (1) shows the schematic process for the synthesis of MIP. The special binding sites are formed by the self-assembly of the template with functional group and the monomer, followed by a crosslinked co-polymerization. After the polymerization, the template is removed from the polymer by Soxhlet extraction, leaving recognition sites that, in terms of size, shape and functionality, are complementary to the template. So, ideally, the resulting MIP can selectively re-bind the template in preference to other closely related structures. The effectiveness of the template removal was evaluated by determining the concentration of caffeine in Soxhlet extract using high-performance liquid chromatography (HPLC). Approximately, $99.6 \%$ caffeine removal was achieved.

\section{Selectivity of the MIPs}

The selectivity and efficiency of MISPE were evaluated and compared with conventional $\mathrm{C}_{18}$ using spike samples and several coffee samples from different brands. Fig. (2a and $\mathbf{2 b}$ ) show the chromatograms of caffeine obtained from spiked samples $(10 \mu \mathrm{g} / \mathrm{mL})$ extracted using MISPE and $C_{18}$, respectively. Based on the GC area, the amount of caffeine 

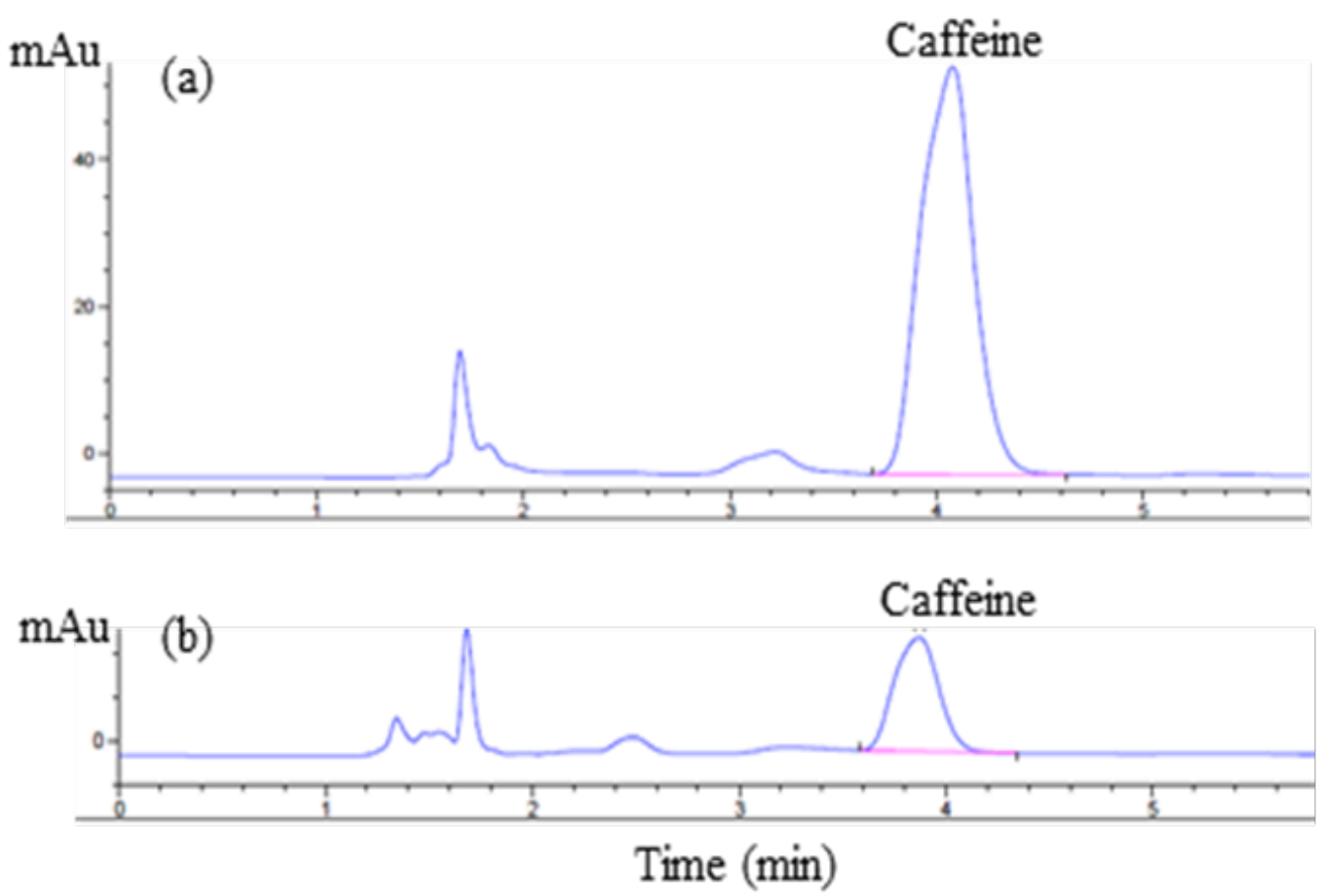

Fig. (2). Chromatograms of caffeine extracted using MISPE (a) $\mathrm{C}_{18}-\mathrm{SPE}$ (b).

Table 1. Recovery of Caffeine from Spiked Samples $(10 \mu \mathrm{g} / \mathrm{mL})$ Extracted on Different Type of SPE Sorbent.

\begin{tabular}{|c|c|c|}
\hline Type of SPE Sorbent & Recovery (\%), $\mathbf{n}=\mathbf{3}$ & RSD (\%) \\
\hline \hline MIPS & 91.6 & 0.9 \\
C $_{18}$ & 63.8 & 5.3 \\
\hline
\end{tabular}

Table 2. Amount of Caffeine $(\mu \mathrm{g} / \mathrm{mL})$ in Five Coffee Samples of Different Brands Extracted Using MISPE.

\begin{tabular}{|c|c|c|}
\hline Sample & Amount $(\boldsymbol{\mu g} / \mathbf{m L})$ & RSD (\%) \\
\hline \hline A & 9.98 & 4.74 \\
\hline B & 4.62 & 8.86 \\
\hline C & 15.60 & 8.82 \\
\hline D & 9.62 & 1.44 \\
\hline E & 21.17 & 2.96 \\
\hline
\end{tabular}

extracted using MISPE almost twice compared to that extracted using $\mathrm{C}_{18}$ sorbent.

Table 1 shows percentage recoveries of caffeine using three replication of MIPs and $\mathrm{C}_{18}$ from standard solutions (10 $\mu \mathrm{g} / \mathrm{mL})$. Methanol and mixture of methanol/acetic acid (90: $10, \mathrm{v} / \mathrm{v}$ ) were used as the washing and eluting solvents, respectively. From the results, one can note that higher affinity and recovery were obtained on MISPE (91.8\%) than $\mathrm{C}_{18}(63.8 \%)$. The results concurred with the study conducted by Wang et al. 2004. This is due to the specific binding of the MIPs to the template and the analogue. When comparing the results of MIPs with that of $\mathrm{C}_{18}$, it can be seen that $\mathrm{C}_{18}$ has lower recovery of caffeine. In all cases, the repeatability of MIPs was found to be excellent $(0.9 \%)$ compare to $\mathrm{C}_{18}$ $(5.3 \%)$.

In comparison with traditional stationary phase extraction materials such as $\mathrm{C}_{18}$, a unique property of MIP is their lockkey relationship with the target molecule (Fig. 1), and hence their selectivity can be predetermined. The result showed MISPE is a well-recognized technique for the selective extraction and pre-concentration of analytes present in low levels in chemically complex samples. The calibration curve of caffeine was linear from $0.25-50 \mu \mathrm{g} / \mathrm{mL}$, with the correlation coefficient $\left(\mathrm{r}^{2}\right)$ of 0.9977 . Table 2 tabulates the amount of caffeine obtained from coffee samples was in the range of 4.62 to $21.17 \mu \mathrm{g} / \mathrm{mL}$. Acceptable precision $(<9 \%)$ was obtained from all samples. 


\section{CONCLUSION}

In this work, caffeine molecular imprinted polymer (MIP) was successfully synthesised. The MIP was used for solid phase extraction (MISPE) for the extraction of caffeine from spiked samples and several coffee samples of different brands. The synthesised MIPs showed high selectivity to the target molecules. It was observed that high affinity and recovery of caffeine $(91.6 \pm 0.9 \%)$ was obtained on the MISPE cartridge than conventional $\mathrm{C}_{18}$. Due to the excellent selectivity, MIP is a good alternative for the extraction of compounds from a complex matrix such as plant extract.

\section{CONFLICT OF INTEREST}

The authors confirm that this article content has no conflicts of interest.

\section{ACKNOWLEDGEMENTS}

The authors would like to acknowledge the financial support of this project by Universiti Teknologi MARA (Project number: 600-RMI/DANA 5/3/RIF (69/2012)).

\section{REFERENCES}

[1] Smith, A. Effects of caffeine on human behavior. Food Chem. Toxicol., 2002, 40, 1243-1255.
[2] Temple, J. L. Caffeine use in children: What we know, what we have left to learn, and why we should worry. Neurosci. Biobehav. Rev., 2009, 33, 793-806.

[3] He, C.Y., Liu, F., Li, K.A., Liu, H.W. Molecularly imprinted polymer film grafted from porous silica for selective recognition of testosterone. Anal. Lett., 2006, 39, 275-286.

[4] Yang, H.H., Zhang, S.Q., Tan, F., Zhuang, Z.X., Wang, X.R. Surface molecularly imprinted nanowires for biorecognition. $J$. Am. Chem. Soc., 2005, 127, 1378-1379.

[5] Theodoridis, G., Manesiotis, P. Selective solid-phase extraction sorbent for caffeine made by molecular imprinting. J Chromatogr. A, 2002, 948(2002), 163-169.

[6] Farrington, K., Magnerb, E., Regan, F. Predicting the performance of molecularly imprinted polymers: Selective extraction of caffeine by molecularly imprinted solid phase extraction. Anal. Chim. Acta., 2006, 566, 60-68.

[7] He, C., Long, Y., Pan, J., Li, K, Liu, F. Application of molecularly imprinted polymers to solid-phase extraction of analytes from real samples. J. Biochem. Biophys. Methods, 2007, 70, 133-150.

[8] Martín, E. A. Molecularly imprinted polymers: new molecular recognition materials for selective solid-phase extraction of organic compounds. Fresenius. J. Anal. Chem., 2001, 370, 795-802.

[9] Andersson, L.I. Selective solid-phase extraction of bio- and environmental samples using molecularly imprinted polymers. Bioseparation 2001, 10, 353-364.

[10] Baggiani, C., Anfossi, L. and Giovannoli, C. Solid phase extraction of food contaminants using molecular imprinted polymers. Anal. Chim Acta, 2009, 591, 29-39.

[11] Wang, D., Hong, S.P. Row, K. H. Solid extraction of caffeine and theophylline from green tea by molecular imprinted polymers. korean J. Chem. Eng., 2004, 21(4), 853-857. 